Dirección

Departamento de Historia Medieval y Moderna Facultad de Geografía e Historia Plaza de la Universidad, 1 15782 - Santiago de Compostela - España cbarros17@gmail.com

\section{HISTORIOGRAFÍA DE VALORES: UN DEBATE NECESARIO*}

\author{
Carlos Barros*
}

Universidad de Santiago de Compostela

Santiago de Compostela - Espanha

\title{
Resumen
}

Los conceptos de passado, presente, futuro o compromiso del historiador han sido fundamentales para entender la revolución historiográfica del siglo XX protagonizada por la historiografía marxista y la escuela de Annales. Se trata ahora de actualizarlos de manera autocrítica, recogiendo las prácticas historiográficas actuales más avanzadas. Proponemos sustituir cualquier "historia militante" de tipo político o religioso por una "historiografía de valores". La generalización en la sociedad global de los grandes valores sociales, políticos y económicos, y los derechos humanos hace posible una nueva referencia deontológica para el oficio de historiador y la utilidad social de la historia en el siglo XXI.

\section{Palavras-chave}

Historia - siglo XXI - compromiso.

* Versión escrita, actualizada, ampliada y revisada en junio de 2017, de mi conferencia plenaria en el IV Congreso Internacional Historia a Debate. Santiago de Compostela, 16 de diciembre de 2010 (vídeo en http://youtube/MVCu9TjMVVw).

* Profesor Titular de Historia Medieval de la Universidad de Santiago de Compostela y Coordinador del Grupo de Investigaciones Historiográficas en la misma institución. 


\title{
HISTORY OF VALUES: A NECESSARY DEBATE
}

Contact

Departamento de Historia Medieval y Moderna Facultad de Geografía e Historia Plaza de la Universidad, 1 15782 - Santiago de Compostela - España cbarros17@gmail.com

\section{Carlos Barros}

Universidad de Santiago de Compostela

Santiago de Compostela - Espanha

\begin{abstract}
The concepts of past, present, future and the Historian commitment has been essential to understand the historiographical revolution of the twentieth century led by Marxist historiography and the Annales school. It is now time to update self-critical manner, picking the most advanced current historiographical practices. We propose to replace any "militant history" of political or religious by a "historiography of values". The generalization in the global society of the great social, political and economic values, and human rights, enables a new ethical reference for the historical profession and social usefulness of history in the XXI century.
\end{abstract}

\section{Keywords}

History - XXI century - commitment. 
Queremos volver hoy en este IV Congreso Internacional de Historia a Debate, en plena madurez de nuestra red y movimiento historiográfico, sobre el viejo asunto de la utilidad social de la historia y el compromiso del historiador, cuya puesta en práctica de forma nueva explica en buena parte la expansión y continuidad ${ }^{1}$ de Historia a Debate, que acaba de cumplir sus 20 años. $^{2}$ También que estemos tantos aquí en Compostela ${ }^{3}$ y en la red, siguiendo esta conferencia sobre el oficio de historiador en el siglo XXI.

\section{Una ética para la historia}

He bautizado lo que venimos haciendo desde HaD "historiografía de valores", ${ }^{4}$ copiando de los didactas ${ }^{5}$ que han desarrollado la "educación en

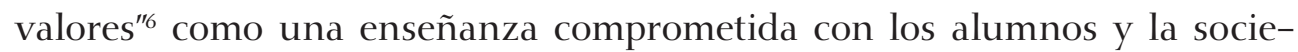
dad a la que servimos, mejor dicho, a la que deberíamos servir.7 Valores de

\footnotetext{
1 Fruto de una renovación continua del continente (formatos de comunicación) y del contenido (paradigmas compartidos): marcada en los últimos años, en el primer caso, por el salto a las nuevas redes sociales (HaD, desde los congresos a las redes sociales. In: https://www.youtube. $\mathrm{com} /$ watch? $\mathrm{v}=\mathrm{kl} 6 \mathrm{TsMm}(\mathrm{waU})$, y en el segundo caso por el reciente desarrollo de tres ámbitos de reflexión e investigación escasamente presentes en el Manifiesto de hace 13 años: historia inmediata, memoria histórica y nuevo paradigma educativo de la historia.

2 Sobre el XX aniversario de HaD, ver la circular del 12 de julio de 2013, donde planteamos el paso del debate al consenso como plataforma historiográfica, iniciado con el Manifiesto historiográfico de 2001. In: http://www.h-debate.com/Spanish/aniversarios/varios/v_a/menu.htm.

3 Algunos de los que participaron en nuestro I Congreso de 1993, o leyeron sus actas, todavía útiles hoy, pensaron que hablando de Annales, past and present, la microhistoria o la historia cultural, ya estaba "todo" dicho, qué equivocados estaban: la historia que nos rodea siguió evolucionando y con ella la historiografía.

${ }^{4}$ Expresión utilizada por vez primera en una entrevista sobre el fraude electoral en México para La Jornada, México D. F., 3 de agosto de 2006 (http://www.h-debate.com/cbarros/spanish/ entrevistas/mexico.htm).

${ }^{5}$ GONZÁLEZ LUCINI, Fernando. Educación ética y transversalidad. Cuadernos de pedagogía, ${ }^{\circ}{ }^{227}$, Barcelona, 1994, p. 10-13; BAILLY, Antoine. La educación para las nuevas ciudadanías mediante la historia y la geografía: enfoque teórico. Perspectivas: revista trimestral de educación comparada, $\mathrm{n}^{\circ}$ 2, Unesco, 1998, p. 223-229; CORTINA, Adela. El mundo de los valores. Ética y educación. Bogotá: Editorial El Buho Ltda, 1997 (https://bioetica260.files.wordpress.com/2016/03/adela-cortina-el-mundo-de-los-valores.pdf).

${ }^{6}$ La "educación en valores" viene a ser alternativa de la oficial y obligatoria "educación en competencias", si bien nosotros defendemos combinar ambas de manera que los "valores" inspiren las "competencias". BARROS, Carlos. Didáctica de la historia, ¿valores o competencias? Conferencia para la Televisión Educativa del Gobierno federal mexicano. México D. F., 6 de diciembre de 2011 (http://youtu.be/ZlYEnkppfWc).

7 Deber académico aunque sólo fuese porque es la sociedad quien paga, a través de los impuestos, nuestros salarios, contratos y becas para enseñar e investigar la historia.
} 
ámbito general e inclusivo que muchos tenemos en cuenta a la hora de la investigar y enseñar, son parte esencial de esa alianza entre historiografía y didáctica de la historia que proponemos, desde el universo académico latino, como "nuevo paradigma educativo de la historia".

Tal como va el siglo XXI, la historia debe ser más que nunca la maestra de la vida. Contribuyendo a un mundo mejor para nuestros hijos y conciudadanos, lo dijo Marc Bloch en Métier d'historien, está en los estatutos de nuestras universidades y obliga especialmente a las ciencias humanas y sociales. Aclarando previamente que reivindicar una historiografía de valores no es tanto que el profesor de historia deba transmitir valores universales (como el resto de los docentes universitarios y no universitarios), que también, como dotarnos de una deontología profesional actualizada que ilumine la educación, la investigación y la divulgación de la historia, que no debemos entender como compartimentos estancos.

La historia académica ha perdido pulso desde finales del siglo $\mathrm{XX}$, urge que recupere credibilidad y presencia social,9 aquí y ahora, cuando todos se interesan por la historia, no sólo los viejos Estados, también otros sujetos políticos y sociales $^{10}$ que buscan su identidad (social, nacional, étnica, de género) y su futuro en la historia. ${ }^{11}$ Tanta atención es buena para el porvenir de nuestra disciplina, pero también exige a los historiadores no huir del presente $^{12}$ antes bien abordarlo en su devenir. Necesitamos un compromiso deontológico que nos permita movernos, con obligaciones y sin temores,

\footnotetext{
${ }_{8}^{8}$ Propuestas para el nuevo paradigma educativo de la historia. Sarmiento. Anuario Galego de Historia da Educación, $\mathrm{n}^{\circ}$ 12, Universidades de Santiago, A Coruña y Vigo, 2008, p. 127-152 (www.h-debate. com/cbarros/spanish/articulos/nuevo_paradigma/npeducativo.htm).

9 Deteriorada por el retorno al positivismo, por parte de historiadores ex annalistes y ex marxistas, lo que ha provocado una brecha inquietante entre historia y sociedad al tiempo que un mayor peso en la historiografía de las instituciones políticas y los media. BARROS, Carlos. Oficio de historiador, inuevo paradigma o positivismo? In: IX Seminário Nacional de Estudos e Pesquisas História, Educaçao e Sociedade no Brasil. João Pessoa, Brasil, 2012 (https://www. academia. edu/5730688/Oficio_de_historiador_nuevo_paradigma_o_positivismo).

${ }^{10}$ Inclusive el movimiento indignado del 15M se interesaba por la historia cuando rechazaba la historia oficial de la transición a la democracia en España.

${ }^{11}$ También la novela depende en el siglo XXI de la historia para mantenerse a flote, en mayor medida que en el siglo XX. BARROS, Carlos. El retorno de la historia. Historia a debate. I. Cambio de siglo. Santiago: Historia a Debate, 2000, p. 153-173 (http://www.h-debate.com/cbarros/spanish/articulos/nuevo_paradigma/retornohistoria.htm).

${ }^{12}$ Los ataques defensivos al "presentismo" se han convertido en lugar común entre los historiadores retornados que reniegan conocer el pasado a través del presente, y viceversa, como decían los primeros Annales.
} 
entre el pasado, el presente y el futuro. Eludiendo la comodidad del academicismo, coartada frecuente para "escapar" de la realidad histórica y actual, preñadas de futuros alternativos. Aggiornamento concreto pues, histórico-real, cultural, social y político, no basado tanto en un partido, una ideología o en una religión, como en valores socialmente compartidos que aseguren nuestra autonomía profesional-ciudadana.

Los colegas de sicología social definen los valores como creencias estables y colectivas (vienen del latín 'valere" que significa "ser fuerte"): sujetas como todo a una evolución histórica, añadimos nosotros. ${ }^{13}$ Pugnamos por una nueva historiografía de valores en lo profesional y lo no profesional, social e historiográficamente eficaces, sin autocensuras ni aislamientos corporativos. Valores que definan los más importantes usos públicos, sociales y políticos de la historia: aquellos que viene del interior de la propia historiografía. ${ }^{14}$ Es fácil criticar (muchas veces por desacuerdos políticos) ${ }^{15}$ los usos públicos y políticos de la historia que se hacen desde el poder y diversos sujetos políticos y/o sociales, y no tener la inteligencia de explicitar los propios usos públicos, sociales y políticos que se derivan de la selección de temas y fuentes para la investigación, la interpretación y la escritura de la historia que hacemos desde la propia universidad y otros centros de investigación, sometidos por lo demás como instituciones públicas a esos mismos valores de tolerancia, paz, justicia y compromiso democrático que no debemos obviar en la enseñanza y la investigación de la historia o cualquier otra disciplina universitaria.

\section{Globalización de valores}

En el siglo XXI es ineludible y también factible, lo estamos demostrando en la práctica, una nueva historiográfica animada por valores humanos universales. Jamás antes la historia vivió una generalización tan intensa de valores positivos de tipo moral y social, político y jurídico. La transición del siglo XX al siglo XXI está suponiendo que los valores relativos a los derechos humanos y la libertad de las personas, elaborados por la Ilustración y

\footnotetext{
${ }^{15}$ Como historiadores primamos los valores socio-culturales como una ética pragmática, colectiva e histórica, más allá por tanto de lo personal, lo espiritual o lo puramente filosófico.

${ }^{14}$ Está de moda "renegar" la utilización pública de la historia que se infiere voluntaria o involuntariamente del propio trabajo del historiador: como la avestruz suicida que metía la cabeza en un agujero para que no la vieran.

${ }^{15}$ Por ejemplo, los historiadores opuestos a la memoria histórica o a los nacionalismos periféricos en España.
} 
convertidos en ley (con sus limitaciones) por la Revolución Francesa, estén hoy más universalizados, reivindicados y garantizados ${ }^{16}$ que nunca, como consecuencia de un proceso de globalización que afecta más la sociedad civil que a la sociedad política. Generalización que no es exclusivamente geográfica sino también de contenido: los derechos humanos incluyen ahora a todas las personas con independencia de su edad, género, condición sexual, nacionalidad, religión o etnia. Se contemplan así mismo los derechos de los animales y del medio natural. Avance de la humanidad que sigue encontrando graves - y a menudo violentas - resistencias por parte de los viejos poderes e intereses en los diferentes ámbitos de la vida: los mismos que, si pudiesen, acabarían con la autonomía de la universidad y su función crítica al servicio del saber y la sociedad de nuestro tiempo.

Vivimos en estos últimos 15 años, un momento excepcional, lleno de oportunidades para la historia y los historiadores, con esta paradójica globalización que nos permite tanto progresar como ser arrastrados hacia un pretérito lugar ignoto y peligroso para las mayorías sociales. ${ }^{17}$ ¿Cómo podemos contribuir los historiadores a generar mejores alternativas de presente y futuro? Dando perspectiva histórica y sostén a las partes más benéficas de la mundialización en curso: la revolución de las comunicaciones ${ }^{18}$ y la universalización de los valores. Contrapesos imprescindibles de una globalización económica y financiera que domina el mundo de manera antidemocrática. Induciendo la gran crisis y recortando derechos humanos y sociales adquiridos con gran coste: dos caras de la misma moneda.

En el inicio de este proceso paradójico dimos a conocer, el 11 de setiembre de 2001, el Manifiesto historiográfico de Historia a Debate, donde alentamos al compromiso historiográfico con "las causas sociales y políticas vinculadas a la defensa de valores universales de educación y salud, justicia e igualdad, paz y democracia. Actitudes solidarias indispensables para contrarrestar otros compromisos académicos con los grandes poderes económi-

\footnotetext{
${ }^{16}$ Relativamente garantizados: los Estados (empezando por los más poderosos) suelen desobedecer a la ONU y demás organismos internacionales que conminan a que se haga justicia con las violaciones de derechos humanos en sus territorios (como los Estados de EE. UU., China y Rusia; también España en relación con el franquismo).

${ }^{17}$ Tenemos un ejemplo de este retroceso en los países de sur de Europa, más afectados que el resto del mundo por la inacabada y atroz crisis mundial del capitalismo iniciada en 2008.

${ }^{18}$ La revolución de las comunicaciones es, con diferencia, la más interesante de las globalizaciones tecnológicas en curso por sus efectos democráticos y horizontales que vienen posibilitando un nuevo sujeto social y global (desde el altermundismo hasta los indignados) que lucha porque se lleven a la práctica los valores de referencia de la humanidad actual.
} 
cos y políticos, mediáticos y editoriales".19 Palabras, términos y conceptos en los que en principio "todos" estamos de acuerdo pero que, a la hora de su puesta en práctica, sea política sea historiográfica, resulta que unos estamos más de acuerdo que otros.

Hablamos luego de una triple globalización (económica, digital y ético-social) en marcha acelerada, pero falta hablar de la casi ausencia de una cuarta globalización: la globalización política que no arranca. Y donde lo hace fracasa, generando graves desequilibrios de todo orden en el proceso de mundialización en el que estamos inmersos. Véase si no la crisis actual de esa pretensión de gobernanza mundial que implican la ONU o la Unión Europea. Los políticos y las instituciones públicas van manifiestamente retrasados en el proceso de globalización, lamentando en su mayoría, la digan o no, ${ }^{20}$ aquellas formas de globalización que entrañan democratización de la información y extensión de valores, cuya combinación engendra una intervención en la historia de la sociedad civil de importantes dimensiones. La mal llamada "clase política"21 va claramente detrás de los acontecimientos, también cuando se acercan a la historia (sólo les interesan batallas e historia político-institucional), es mejor por consiguiente no seguirlos demasiado, utilicemos la autonomía que reivindicamos para la historia que se escribe para condicionar motu proprio un mejor uso público de la historia. Nadie mejor que el historiador con valores para analizar el presente e interesarse por el futuro, en base a su conocimiento del pasado.

Sería un error histórico, por lo tanto, considerar la globalización como un todo homogéneo y unívoco, está sometida a un desarrollo plural, paralelo y contradictorio. Como decíamos cuando éramos jóvenes estudiantes, la clave de la mundialización está en la "contradicción principal", que se manifiesta de la siguiente forma: la (macro) economía se impone al resto. Ya consiguieron sin grandes esfuerzos y escasos costes domeñar a la política, lo intentan con internet y los humanos valores tan "peligrosamente" divulgados, por servir ambos de soporte a un movimiento social global que no dijo su última palabra. La crisis económica tiene su primera víctima los grandes valores

\footnotetext{
19 Punto XVI del Manifiesto historiográfico de HaD (http://h-debate.com/manifiesto/\#tab-1439460079-2-68).

${ }^{20}$ También grandes - y pequeños - intelectuales del siglo XX que no se ven reflejados en las influyentes tendencias globales, y despotrican continuamente contra internet; un buen ejemplo es Umberto Eco (http://h-debate.com/umberto-eco-2752013/).

${ }^{21}$ Derivación bastarda del concepto marxista de clase social referido al grupo, élite, corporación o nomenklatura que conforman los políticos profesionales en las sociedades contemporáneas.
} 
(siempre en peligro, ahora más) empezando por los derechos sociales que los movimientos sociales tardaron un siglo en conquistar. Las generaciones jóvenes de trabajadores no están disfrutando de los mismos derechos que tuvieron sus padres y abuelos. ${ }^{22}$ Lo mismo se puede decir de los licenciados y graduados en historia y otras disciplinas académicas: no tienen otro camino que enarbolar su derecho a un trabajo digno, de acuerdo con la formación, y al bienestar social, como ciudadanos, universitarios y profesionales. De hecho constituyen la base del movimiento global de los indignados 2011-2014.

Aunque de forma desigual, según la categoría social y el lugar del mundo, la globalización neoliberal nos afecta a todos, a la mayoría de la sociedad. Se dice metafóricamente que, detrás de la mundialización económicamente dominante, está el 1\% de la población decidiendo por el restante 99\% $0 .{ }^{23}$ Con otras palabras: los mercados financieros imponen su lógica a la política y a la sociedad. Con estupefacción hemos ido comprobando como los representantes que elegimos para gobernarnos democráticamente ${ }^{24}$ obedecen par tout, disciplinadamente, a los poderes fácticos que viven de la especulación financiera: nadie los eligió y están gobernando el mundo. Se nombraron a sí mismos y mandan sobre la democracia, uno de los valores compartidos más importantes en este siglo XXI.

Después del control de los gobiernos, vivimos tentativas de acabar con internet por parte de los mercados. Los ataques "preventivos" 25 a la libertad de expresión y la neutralidad de la red tuvieron su máxima y simbólica expresión en el acoso judicial y político a Bradley Manning, Julián Assange y Wikileaks, en 2010, y la persecución de Edward Snowden en 2013. En todos los casos, el protagonista es el Gobierno de los Estados Unidos de larga tradición imperial, intervencionista, que por desgracia no ha desaparecido con

\footnotetext{
${ }^{22}$ Las "reformas" que están acompañando a la crisis tienen como objetivo hacer permanente, estructural, un mercado de trabajo precario con menos salarios y menos derechos.

${ }^{23}$ Uno de los lemas indignados más conocidos: "Somos del 99\%".

${ }^{24}$ El Congreso de Historia a Debate donde se impartió la conferencia que sirve de base a este trabajo tuvo lugar seis meses después de que la crisis virulenta llegara a España, a través de la prima de riesgo y las presiones de las instituciones europeas, plegándose en agosto de 2011 el gobierno de Zapatero y el Congreso de Diputados a la reforma constitucional (artículo 135) que exigía Alemania de dar prioridad al pago de la deuda a los bancos extranjeros, cualesquiera que fuesen los efectos (mortíferos en no pocos casos) de los recortes subsiguientes en la población.

${ }^{25}$ Se pretende castigar y disuadir a quien usa o pueda usar internet en el futuro para criticar a una "primera potencia mundial" debilitada por el verdadero poder de las finanzas y la creciente competencia de las potencias emergentes: la nueva economía global es el verdadero enemigo de los EE. UU., también de la Unión Europea.
} 
la presidencia de Obama. El "delito" es siempre el mismo: la difusión por internet de informaciones sensibles que sacan a la luz la contradicción entre lo que se dice y se hace por parte de los políticos en el poder, norteamericano en este caso. La represión refleja el temor que tienen unos y otros a la inmensa fuerza y eficacia que tiene hoy la red $^{26}$ en favor de los nuevos derechos civiles, que también precisamos los historiadores que trabajamos en red.

Al tiempo que la idea de justicia se fue globalizando, creando o fortaleciendo tribunales internacionales que los Estados democráticos dicen respetar y generando un nuevo derecho internacional en torno al concepto de justicia universal, crecieron las resistencias de los Estados poderosos a sus decisiones, sobre todo cuando afectan a delitos imprescriptibles de lesa humanidad. Verbigracia, el Tribunal Internacional de la Haya de la ONU no reconocido por los EE. UU., o el Tribunal de Derechos Humanos de Estrasburgo del Consejo de Europa incapaz, hoy por hoy, de hacer frente - sirva como ejemplo - al incumplimiento del derecho internacional por parte del Estado español, y otros gobiernos, en temas de memoria histórica: piedra de toque, aquí y ahora, de la calidad de una democracia. La mayoría de los políticos no lo quieren entender: la gente en el siglo XXI es mucho más exigente que en siglo XX. Una democracia sin justicia, e igualdad, de poco vale en estos tiempos. El nuevo concepto de justicia universalista es valor básico tanto de la mentalidad global como de la legalidad internacional, que tienden a imponerse sobre las legalidades locales (nacionales), mal que les pese a algunos. Es el caso de la negativa española a la tutela judicial de las víctimas de los delitos atroces del franquismo. Cuestión que concierne directamente a la historia como disciplina. ${ }^{27}$

Como historiadores-ciudadanos no podemos dejar de indignarnos ante el acoso judicial y político que ha sufrido el juez Baltasar Garzón entre 2010 y 2012 por haber pretendido tutelar judicialmente a las víctimas del franquismo en sus justas reivindicaciones de "verdad, justicia y reparación". ${ }^{28}$ Con su expulsión de la Audiencia Nacional no sólo se quiso amedrentar a otros jue-

\footnotetext{
${ }^{26}$ La paradoja es que la globalización económica no puede acabar con la red de redes que juega un papel clave en el desarrollo de las fuerzas productivas del siglo.

${ }^{27}$ BARROS, Carlos. Historia, memoria y franquismo (2013). En: http://www.h-debate.com/cbarros/ spanish/articulos/memoria/Historia_memoria_y_franquismo.htm.

${ }^{28}$ Declaración sobre los principios fundamentales de justicia para las víctimas de delitos y abuso de poder. Resolución 40/34 de 1985 de la Asamblea General de la ONU.
} 
ces en España ${ }^{29}$ sino golpear las justicias transicional (violaciones masivas de derechos humanos) y universal de las cuales Garzón fue pionero y símbolo, que acaban de sufrir otra vuelta de tuerca con la reciente y arbitraria anulación por parte del Gobierno del PP de los casos de justicia universal que estaban siendo llevados por la Audiencia Nacional desde España. Una vez más se demuestra que la globalización de valores no acepta compartimentos estancos $^{30}$ al gusto de cada poder, país o temática. Convenzámonos, se trata de un proceso históricamente irreversible: los historiadores deberíamos ser los primeros en comprenderlo.

\section{La historia se mueve}

Ante tal encrucijada de valores, realidades y legalidades, ¿qué papel histórico han de jugar la historia y las ciencias sociales, la universidad y los intelectuales en general? ${ }^{31}$ Ninguno, es la primera opción. Seguida por no pocos intelectuales e historiadores que proclaman su "asepsia", echando manos de argumentos "académicos", sabiendo lo injusto que puede ser habiendo tantas cuestiones de candente actualidad y humano contenido que nos reclaman. ${ }^{32}$ Tiene que ver con la vuelta del positivismo, ${ }^{33}$ de la simple erudición, que

\footnotetext{
${ }^{29}$ No lo consiguieron en lo tocante a la corrupción de los políticos, el segundo motivo de la expulsión de Garzón (caso Gürtel), contra la cual se están levantando jueces por doquier.

${ }^{30}$ Los jueces de la Audiencia Nacional han sido ingenuos si pensaban que callando - o lo que es peor, colaborando - cuando desde el Gobierno y la Sala Penal del Tribunal Supremo expulsaron a Garzón, iban a dejarle hacer en otros países lo que el buen juez quería hacer en España: proteger a las víctimas.

${ }^{31}$ En 2009 un filósofo de la Universidad de Toronto hablaba de una "epidemia de conformismo" de los intelectuales ante los mercados: "los intelectuales críticos son una especie en extinción", escribió en http://elpais.com/diario/2009/08/29/opinion/1251496811_850215.html; cinco años después la situación ha cambiado en parte, generacionalmente, en los países donde la crisis y el movimiento indignado de los jóvenes graduados (15M y afines) ha resucitado un compromiso intelectual independiente del poder, que ha reanimado a su vez a un parte de la generación del 1968.

${ }^{32}$ Hace 15 años, calificaba de transitoria la postura "esquizofrénica" de historiadores que se declaraban neutrales en la academia y sin embargo sentían "fuera de la universidad" su compromiso ciudadano, acerté en buena medida. BARROS, Carlos. El compromiso del historiador, hoy. La historia de la historiografía contemporánea en España, curso organizado por la Institución Fernando el Católico y la Universidad de Zaragoza. Zaragoza, 9-11 de diciembre de 1998.

33 Favorecido por el interés resurgido de los Estados y los nacionalismos hacia una historia tradicional de grandes figuras, batallas y hechos de corte político-institucional. BARROS, Carlos. El retorno de la historia. Historia a debate. I. Cambio de siglo. Santiago: Historia a Debate, 2000, p. 153-173 (http://www.h-debate.com/cbarros/spanish/articulos/nuevo_paradigma/retornohistoria.htm).
} 
hemos analizado en detalle recientemente: ${ }^{34}$ se encierran en la academia, escriben sólo para los colegas. Pero somos cada vez más, dentro y fuera de la red Historia a Debate, que persistimos en pensar que Marc Bloch tenía razón, cuando repetía, parafraseando un proverbio árabe, que "el historiador se parece más a su tiempo que a sus padres", añadiendo que "una ciencia tiene algo de incompleto si no nos ayuda a vivir mejor".35 Una parte de la historiografía actual ha olvidado estas verdades, es menester volver a tomar conciencia. Independientemente del tiempo transcurrido desde los hechos que estudiamos, escribimos la historia en el siglo XXI, desde el siglo XXI, incluso sobre el siglo XXI. ${ }^{36}$ No tenemos opción mejor, salvo volver al siglo XIX con Leopold von Ranke, asumiendo el anacronismo que implica, hoy, una historia puramente empírica al margen de la sociedad y de nuestro tiempo. Erudición a la vieja usanza que acredita sorpresivamente como un "avance" la creciente fragmentación de nuestra disciplina en flagrante contradicción con la globalización - en nuestra mejor lectura ${ }^{37}$ - que vivimos, fuente de un "presentismo" que estamos obligados a reformular desde la historia si queremos "vivir mejor" en el futuro, como historiadores y ciudadanos.

Felizmente, amplios sectores de la historiografía académica, no sólo Historia a Debate, vienen reaccionando dinámica y colectivamente en este nuevo siglo, en varias direcciones (no siempre compatibles). A la hora de elaborar el Manifiesto de 2001 detectamos cuatro grandes corrientes historiográficas internacionales más o menos organizadas (retorno al positivismo, continuidad de Annales y marxismo, posmodernismo y nuevos paradigmas como $\mathrm{HaD}$ ) que tienden a converger, en este segundo decenio, alrededor de

\footnotetext{
${ }^{34}$ BARROS, Carlos. Oficio de historiador, inuevo paradigma o positivismo? (2013). En: http:// www.h-debate.com/cbarros/spanish/articulos/nuevo_paradigma/oficio.htm).

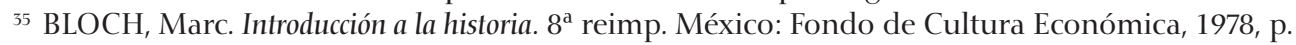
14, 32; citas originales: "Les homes ressemblent plus à leur temps qu'à leurs pères"; "une science nous paraîtra toujours avoir quelque chose d'incomplet si elle ne doit pas, tôt ou tard, nous aider à mieux vivre". BLOCH, Marc. Apologie pour l'histoire ou métier d'historien. Paris: Étienne Bloch édition, 1993, p. 73, 89.

${ }^{36}$ BARROS, Carlos. ¿Es posible una historia inmediata? (2002). En: www.h-debate.com/cbarros/ spanish/articulos/mentalidades/inmediata.htm.

37 A la globalización de los mercados le interesa más una historia acrítica, encerrada en lo nacional, segmentada, donde cada historiador se dedique a "lo suyo", que una historia global en los tres sentidos que le damos al término, mundial, total y digital. Primeras conclusiones del III Congreso Internacional Historia a Debate (14-18 de Julio de 2004). Historia a debate. I. Reconstrucción. Santiago: Historia a Debate, 2009, p. 67-84 (http://cbarros.com/vista-cb/?link=http://h-debate.com/wp-content/old_debates/cbarros/spanish/articulos/nuevo_paradigma/ conclusiones_3had/primeras\%20conclusiones.htm).
} 
dos polos: vuelta a Ranke y nuevo paradigma historiográfico. ${ }^{38}$ En esta tesitura, surgieron en España tres tendencias en los tres últimos lustros, que hemos querido que estuviesen representadas en las conferencias plenarias de este IV Congreso (2010): 1) "Historia a Debate", nacida en 1993 y desarrollada como tendencia global desde 1999; 2) "Idea Histórica de España" que, como movimiento historiográfico animado políticamente por el Gobierno de José María Aznar, podemos considerar originado en 1996; 3) la "Recuperación de la Memoria Histórica" que se inicia con la primera excavación de una fosa de desaparecidos de la Guerra Civil por iniciativa de Emilio Silva y sus colegas en el año 2000. ${ }^{39}$ Muestran el empuje reciente de una historiografía española orgullosamente hija de nuestro tiempo. Todas ellas vinculan claramente el quehacer historiográfico con valores: sea globales (HaD), identitarios (IHE) o memoriales (RMH). Suponen las tres un claro y fructífero regreso al compromiso del historiador en España ${ }^{40}$ que ya había manifestado la intelectualidad de otros países en los años 1990.41 La historiografía española se sitúa así a la vanguardia, dejando atrás el espíritu defensivo, academicista, de

\footnotetext{
$\overline{38}$ Ver mi trabajo sobre el oficio de historiador en el siglo XXI citado en la nota 32.

39 BARROS, Carlos. Las tendencias actuales de la historiografía española (1993-2003). Universidad Nacional a Distancia. A Coruña, 27 de marzo de 2003 (http://h-debate.com/wp-content/ uploads/2015/audio/Las-Tendencias-Actuales-De-La-Historiografia-Espanola-(1993-2003)-A-(27032003)-Carlos-Barros.mp3); Idem. Últimas tendencias de la historiografía española. Montevideo, 2007 (https://www.youtube.com/watch?v=qJCTMfN5yuw).

${ }^{40}$ Seguidores académicos de la Idea Histórica de España y algunos de los practicantes de la Memoria Histórica ocultan en ocasiones - innecesariamente, por lo evidente - sus compromisos sociales y políticos, presumiendo incluso de positivismo para mejor "combatir" a sus adversarios historiográficos y políticos (nacionalismos periféricos en el primer caso; neofranquismo en el segundo), olvidando que hoy más que nunca, objetivamente, la historia sólo puede ser una ciencia con sujeto social y cognoscente (punto I del Manifiesto de HaD).

${ }^{41}$ Lo hemos estudiado en la citada conferencia inédita: BARROS, Carlos. El compromiso del historiador, hoy (Zaragoza, 1998): a partir de la revuelta de Chiapas en 1994 son muchos los intelectuales y académicos mexicanos que apoyaron a los neozapatistas desde las universidades, y, entre 1995 y 1998, hacen lo mismo con los sans-papiers franceses académicos como Jacques Derrida o Pierre Bourdieu, quien confiesa a un entrevistador argentino como "fue víctima de ese moralismo de la neutralidad, del no implicarse, de la no intervención del científico (...) cuanto más envejezco, más me siento empujado al crimen. Transgredo líneas que antes me había prohibido transgredir" (tenía 68 años, morirá con las botas puestas, rodeado de polémica tres años después); Bourdieu crea en ese tiempo cenital el grupo Raisons d'agir en cuyo primer editorial, después de las grandes huelgas de 1995 (que aprovechó nuestro sociólogo para dar un mitin ritual, transgresor, con megáfono en mano a las puertas de la Peugeot), convoca a "poner a disposición del movimiento social el trabajo de los sociólogos, psicólogos e historiadores" buscando poner fin a la "frontera entre trabajo científico y militantismo rehabilitando la polémica". Bourdieu y el "problema Bourdieu". El viejo problema: la ciencia social y la militancia social. Página 12, Buenos Aires, 4 de octubre de 1998.
} 
fines del siglo XX. Si bien no todo lo que se mueve últimamente entre los historiadores españoles mira hacia adelante: el fantasma positivista también se aparece ante historiadores españoles de distinto origen historiográfico y político, en palmaria contradicción a veces con sus prácticas.

En Estados Unidos se han dado paralelamente fenómenos historiográficos de interesante adaptación de los historiadores a nuestro tiempo. En nuestro III Congreso (2004) abrimos un espacio a la World History, ${ }^{42}$ con precedentes en los años 1970 pero desarrollada, gracias al auge de la globalización, a finales del siglo XX. Si bien no todos sus adeptos consideran esta historia global como parte de un nuevo concepto de historia o paradigma ${ }_{r}^{43}$ ven solamente una "nueva" etiqueta, tema de investigación o materia de enseñanza (tradicionalmente "Historia Universal"). Y en este IV Congreso (2010), dedicamos un apartado a la Public History, ${ }^{44}$ también llamada "historia aplicada". Una vía útil para superar la historia endogámica, corporativa y academicista (colegas que escriben para otros colegas), ${ }^{45}$ pero no suficiente para responder a los retos del siglo XX. Línea de investigación que considera como sujeto (tema de estudio) y objeto (objetivo de la investigación) la presencia pública de la historia: condenada a un escaso recorrido si se automargina del debate por un nuevo paradigma (global y comprometido) para la historia.

Lo bueno de la historia pública es su intención de rebasar la vieja relación entre investigación y divulgación, que viene reduciendo ésta a un papel subordinado, escasamente reconocido, antes bien penalizado en las evaluaciones académicas. Pero no siempre busca analizar el historiador público el cómo y el porqué de la escritura de la historia que se aplica a través de la enseñanza, los museos, las bibliotecas, los medios de comunicación, la literatura, el cine, la televisión o internet. La historia pública podría elevar, como parte de una alternativa paradigmática más general, la denostada vulgarización de la historia al nivel de la historia académica. De hecho se le viene dedicando ya un espacio en algunas universidades anglosajonas. ${ }^{46}$

\footnotetext{
${ }^{42}$ Ver World History Association (http://www.thewha.org/).

${ }^{43} \mathrm{Al}$ igual que otras líneas avanzadas de investigación como la historia oral, de género, ecológica, pública o digital: incapaces de ver, prisioneras de la especialización, cómo la aplicación consecuente de sus postulados cuestiona la epistemología de la historia que han heredado.

${ }^{44}$ Ver National Council on Public History (http://ncph.org/cms/)

${ }^{45}$ Es todavía peor cuando se escribe ante todo para el curriculum vitae: necesidad de jóvenes que comienzan a investigar trasmutada después en virtud.

${ }^{46}$ En EE. UU. y otros países y universidades de influencia anglófona se suelen organizar con ese nombre másteres y cursos orientados a las salidas laborales (lo que no es poca cosa, ciertamente): por desgracia, no todos los practicantes consideran la Public History como una manera
} 
Además de revalorizar la difusión o aplicación de la historia, como parte significativa del proceso de conocimiento histórico, la historia pública debería tomar en consideración que una parte creciente de la investigación en historia la hacen ya historiadores que trabajan fuera de la universidad ${ }^{47}$ incluidas tesis doctorales. Reconocimiento y ampliación del campo de trabajo historiográfico que contradice la recuperada idea positivista (contraria en principio a la propuesta Public History) de que el "uso público de la historia" es cosa de "otros", ${ }^{48}$ no de los profesionales de la historia: añoranza infausta de un monopolio corporativo de la historia para los historiadores más "académicos" que suelen tachar de "manipulación histórica" toda posición, iniciativa o conmemoración histórica llevada a cabo por parte de cualquier sujeto político del presente. ${ }^{49}$ De generalizarse estos valores corporativistas, el perjuicio para la disciplina de la historia sería enorme: levantan muros con la sociedad de nuestro tiempo en el momento que precisamos del máximo apoyo público para sobrevivir a globalización. En resumen, sí a una historia pública desde la academia pero con sólidos y comprometidos valores profesionales y sociales que la orienten: rigor y ética, tolerancia y compromiso, pluralidad y debate, sin imposiciones jerárquicas, academicistas o descalificaciones apriorísticas. ${ }^{50}$

Mientras en las universidades norteamericanas, con fama de abiertas, grupos amplios de historiadores buscan acercarse a lo global y asumen el valor de lo público, en Francia la historiografía post-Annales escapa de la calle en pleno siglo XXI, al contrario de lo que hicieran Pierre Bourdieu ${ }^{51}$ o Ja-

distinta de hacer historia, asumiendo por tanto el carácter subalterno respecto de la historia académica tradicional.

${ }^{47}$ Por ejemplo, la mayoría de los historiadores que colaboran en España con la memoria histórica o estudian la historia local, son profesores de enseñanza media.

${ }^{48}$ Ver la nota 12.

49 Salvo que se trate de un actor político de la simpatía del historiador, lo que añade una dimensión perversa a ciertas "denuncias" hiperacadémicas contra los "usos políticos de la historia".

${ }^{50}$ Valores ausentes en políticos e historiadores que han atacado, según veremos, el rigor, la libertad de investigación y compromiso de los historiadores catalanes participantes en el congreso “España contra Cataluña. Una mirada histórica (1714-2014)" celebrado en diciembre de 2013.

${ }^{51}$ Ver la nota 39. 
cques Derrida ${ }^{52}$ en la década anterior. ${ }^{53}$ En 2005, Olivier Pétré-Grenouilleau, profesor de Historia en el conservador Institut d'études politiques de París, fue denunciado ante un juez por el Collectif des Antillais, Guyanais, Réunionnais por justificar la esclavitud (crimen contra la humanidad en Francia):54 "La traite n'avait pas pour but d'exterminer un peuple. L'esclave était un bien qui avait une valeur marchande qu'on voulait faire travailler le plus posible. ${ }^{\prime 5} \mathrm{La}$ asociación de los descendientes de esclavos renuncia finalmente a la aplicación penal de la loi memorielle del 21 de mayo de 2001, retira la querella en febrero de 2006 asumiendo por tanto la primacía de la libertad de expresión e investigación: ayudó la presión de los historiadores que firmaron el escrito radical de Nora contra las leyes memoriales, pese a no nombrar el caso Pétré-Grenouilleau.

Nos parece magnífico que también se defienda en Francia la libertad de la historia, no tanto que Pierre Nora, viejo partisan del positivismo acontecimiental ${ }_{1}^{56}$ al tiempo que historiador interesado por el presente, haya aprovechado que el Pisuerga pasa por Valladolid, como decimos en España, para dar un último golpe de tuerca a los retours conservadores en la historiografía francesa organizando la asociación Liberté pour l'histoire que "exige" en su manifiesto una especie de gremial "historia para los historiadores", enfrentando de manera suicida la historia académica francesa con la sociedad y la memoria de nuestro tiempo, que tiene en Francia su máxima expresión en las polémicas leyes memoriales, de intención progresista en su mayor parte. ${ }^{57}$ La negativa posterior de Pierre Nora a apoyar al juez Garzón en su pre-

\footnotetext{
${ }^{52}$ Siempre crítico, Jacques Derrida, clasificado injustamente de posmoderno en los EE. UU., escribe Spectres de Marx en 1993 contra el dogma del fin del marxismo: 20 años después la actual crisis global del capitalismo confirma su tesis. DERRIDA, Jacques. Spectres de Marx. Paris: Éditions Galilée, 1993.

53 Bourdieu y Derrida estaban de la EHESS pero no eran historiadores, menos dados al compromiso con la excepción de las inquietudes y prolongada experiencia de historia aplicada de Jacques Le Goff, el último annaliste, jubilado en 1994 y recientemente fallecido.

${ }^{54}$ Journal du dimanche, París, 12/6/2005; ver la crítica a Pétré-Grenouilleau de la presidenta de la asociación Survie, TOBNER, Odile. Le racisme français. París: Les Arènes, 2007, y también Une négrophobie académique: Olivier Pétré-Grenouilleau, ou la banalisation de la Traite. Les mots sont importants.net, 4/12/2007 (http://lmsi.net/Une-negrophobie-academique).

${ }^{55}$ La cita viene a decir que la economía es lo primero y las personas después, muy neoliberal pues: el historiador del comercio de esclavos tiene sus valores pero no son los nuestros, ni convienen ese tipo de inhumanas justificaciones a nuestra disciplina y su futuro.

${ }^{56}$ NORA, Pierre. Le retour de l'évènement. In: LE GOFF, Jacques \& NORA, Pierre (dir.). Faire l'histoire, tomo I, París: NRF, Gallimard, 1974.

${ }^{57}$ Hay leyes memoriales contra el holocausto, la esclavitud y el genocidio armenio, más una cuarta de signo conservador, nostálgica del colonialismo francés. BARROS, Carlos. Historia,
} 
tensión de investigar en sede judicial la represión franquista, ${ }^{58}$ como le fue solicitado por el hispanista Bartolomé Bennasar en aplicación del principio de Liberté pour l'histoire, viene a demostrar que la libertad de la historia tiene diferentes, incluso contrapuestas, lecturas y puestas en práctica según sean las ideologías de sus promotores.

Valoramos en parte positivamente este neoconservadurismo historiográfico francés que siguió a los progresistas Annales por lo que tiene de reconexión historia-sociedad, lógicamente plural, crucial para el presente y el futuro de nuestra disciplina. Los valores que sustentan los nuevos compromisos de historiadores - en el caso francés, clandestinamente - están naturalmente a debate, que ha de ser abierto y transparente, sin parapetarse en una incierta e imposible "imparcialidad"59 para así "disparar" mejor sobre los interlocutores historiográficos, sociales o políticos acusados por lo regular de "intrusismo", como si la historia fuese "propiedad" del historiador que la escribe. ${ }^{60}$ Más debates pues sobre nuestros valores profesionales y sociales como investigadores y profesores de historia que han de tener como norte, más allá de la legítima subjetividad individual o de grupo, el interés general de la historia como oficio y disciplina, evitando el funesto equívoco de que por estar nuestro objeto de estudio en el pasado tengamos que callar frente a todo lo que tienen históricamente de tradicional, conservador y reaccionario las sociedades actuales. ¿Si no, para qué sirve la historia?

\section{Compromiso y futuro}

La práctica exitosa de Historia a Debate enseña que el futuro de la historia, y de las ciencias que no hayan perdido su vocación de sociales, está en el reencuentro con la parte más dinámica y sana - éticamente hablando - de la sociedad, hoy más global que nunca. Así fue en el pasado con la "revolución historiográfica del siglo XX": lo estamos intentando un siglo después desde el universo académico latino con otros contenidos y otras formas.

memoria y franquismo (2013). En: http://www.h-debate.com/cbarros/spanish/articulos/memoria/Historia_memoria_y_franquismo.htm.

${ }^{58}$ Ver al artículo citado en la nota anterior.

${ }^{59}$ No querer comprometerse - al menos abiertamente - es otra forma de comprometerse, de tipo conservador por lo general.

${ }^{60}$ La diferencia entre historiadores académicos y aficionados reside en la mayor formación y credibilidad de los primeros, pero ello no debe ser patente de corso para orientar la historia desde malos valores, habitualmente implícitos. 
La primera novedad del siglo XXI es que ahora, con la globalización de valores, no se puede dejar de incluir - a riesgo de marginación social - en lugar preeminente, entre los valores compartidos por los historiadores-ciudadanos: la tolerancia, el respeto mutuo y la pluralidad, hacia dentro y hacia afuera de nuestra profesión. Lo venimos haciendo desde 1993 en

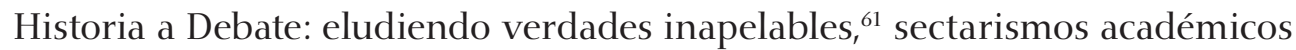
y/o políticos ${ }^{62}$ sin perder de vista como objetivo principal la construcción de un nuevo paradigma o consenso, beneficiándonos a tal fin del diálo-

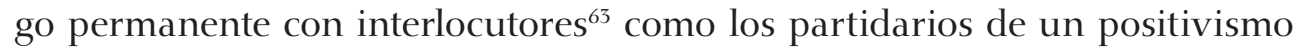
reencontrado, del postmodernismo ficcionado o - en menor medida, son aliados $^{64}$ - del simple continuismo respecto de la historiografía de los años 1960 y 1970. Interrelacionando reflexión con práctica al tiempo que interactuamos con nuestros "adversarios", ${ }^{65}$ hemos ido dando forma a un paradigma-consenso específico, del que todavía no son plenamente conscientes parte de los colegas que han ido participado individualmente en nuestras múltiples iniciativas y debates durante las dos pasadas décadas. Todo ello sin imponer a nadie los puntos del Manifiesto de Historia a Debate (2001), tampoco mis elaboraciones, orientaciones y reorientaciones, como fundador y coordinador al calor de las acciones y reacciones, dentro y fuera de HaD. ${ }^{66}$ Evitando siempre el estilo vaquero de George W. Bush, durante la guerra de Irak, de estás conmigo o contra mí, algo bastante socorrido por cierto tanto en la historia como en la historiografía del siglo XX. Defendiendo las posiciones que consideramos justas y necesarias para la disciplina, sin pretender

\footnotetext{
${ }^{61}$ En la ciencia actual las verdades evitan el idealismo filosófico a modo de creencias religiosas son relativas en el sentido de verdades condicionadas por el sujeto investigador.

${ }^{62}$ Nuestras acciones como Academia Solidaria de Historia a Debate (http://h-debate.com/academia-solidaria-2/) han chocado alguna que otra vez con ultras de derecha (v. g., diciembre 2013, campaña en favor de los historiadores catalanistas) o izquierda (febrero de 2014, en defensa de Garzón boicoteado en la Universidad de Santiago de Compostela).

${ }^{63} \mathrm{HaD}$ es un fenómeno académico poliédrico, foro para unos y tendencia para otros, ambas cosas simultáneamente en realidad: hacer del debate un uso académico supone en sí mismo un cambio de tendencia historiográfica.

${ }^{64}$ Según regresa el positivismo, tenemos que dedicar más tiempo como HaD a explicar la mucha razón que tenían las vanguardias historiográficas del siglo XX en su crítica al empirismo, elitismo y descriptivismo de la escuela alemana del siglo XIX: los continuistas de las nuevas historias del siglo XX han ido descuidando el debate conforme la decadencia de Annales y marxismo se hizo evidente en los años 1980 y 1990.

${ }^{65}$ Sectarismos académicos todavía vivos cuando un colega dice lapidariamente de un tema, enfoque o método: "no me interesa".

${ }^{66}$ Ver http://www.h-debate.com/cbarros/spanish/paradigm_had.htm.
} 
"caer bien" a todo el mundo, cualquiera puede y podrá expresar desacuerdos (educadamente) dentro de nuestro extenso movimiento-red. ${ }^{67}$ Preconizamos en resumidas cuentas un pensamiento crítico, como solíamos decir en los años 1960 y 1970, auténtico y consecuente, crítico y autocrítico, hacia atrás y hacia adelante, de modo que nuestras propuestas paradigmáticas se hacen móviles, varían con el tiempo.

La segunda gran novedad, en la tarea emprendida de redefinir el oficio de historiador para este nuevo siglo, es que ahora, lo vemos por doquier, el compromiso intelectual o académico es menos individual o ideológico, militante o partidista, como en años 1960 y 1970, ${ }^{68}$ y más colectivo y profesional, en tanto que investigadores, enseñantes y practicantes de la historia. Pasa igual con otros oficios y campos académico-profesionales. Compromiso desde la profesión que sólo es realizable si se reemplazan ideologías y religiones por grandes valores ${ }^{69}$ que a veces chocan con aquéllas. ${ }^{70}$

Antonio Duplá en una vieja reseña (2004) sobre Historia a Debate ${ }^{71}$ nos calificaba como "historiadores sin fronteras", a partir de la paradigmática experiencia de médicos y periodistas sin fronteras. Justa equiparación en cuanto a compromiso, sin embargo nuestra red / movimiento historiográfico es bifronte: atiende tanto a la investigación, el debate y la reflexión historiográfica (nuestra primera causa y ocupación) como a lo que sucede en el mundo, especialmente si tiene relevancia histórica e historiográfica. Más todavía en el caso de los que militamos en "cambiar el mundo" en los años 1960-70 con mayor o menor éxito, según qué lugares y continentes. En el caso español, podemos considerarnos regularmente satisfechos, si nos

\footnotetext{
${ }^{67}$ Nuestra capacidad para interiorizar la pluralidad y retroalimentarnos con las críticas explica que no conozcamos críticas académicas externas y públicas, explícitas y por lo tanto confesables.

${ }^{68}$ La historia militante o activista en función de un discurso político o religioso también es legítima, faltaba más, sobre todo si no se esconde, como ha hecho tradicionalmente la derecha académica, pero sirve de poco hoy en día, en plena sociedad de información, más bien perjudica a sus fines.

${ }^{69}$ Obviamente las ideologías y las creencias condicionan las visiones concretas que tiene tal o cual sector social, político, religioso o nacional sobre la justicia, la igualdad, la paz, la ecología, la educación, la salud o la democracia, pero ello no disminuye la universalidad y transversalidad de estos y otros valores y derechos humanos, más bien lo contrario.

${ }^{70}$ El mejor favor que el historiador activo política o religiosamente puede hacer "a los suyos" es emplear criterios de verdad y honestidad cuando crea que las enseñanzas de la historia y una historiografía de valores puede permitir mejorar o rectificar a sus referentes.

${ }^{71}$ DUPLÁ, Antonio. Historiadores sin fronteras, 2004 (http://www.pensamientocritico.org/antdup0404.htm).
} 
atenemos al duro contexto de aquellos años dictatoriales. ${ }^{72}$ Unos cambiaron de ideas y valores, legítimamente. Otros optamos por mantener un hilo conductor biográfico y generacional en los diversos campos académicos y profesionales dónde venido trabajando, que reverdece y se endurece en defensa nuestra disciplina histórica, oficio y universitas en tiempo de retroceso de conquistas sociales, universitarias y políticas. Procurando no separar de manera farisea el historiador del ciudadano, sobre todo en aquellas áreas de nuestro ámbito académico más públicas y actuales, el compromiso social y político del historiador ha de ser profesional y autónomo. ${ }^{73}$

En el siglo XIX, y también en el siglo XX, se separó temerariamente el historiador del ciudadano, el académico del hombre, la historia de su contexto, lo que pudo dificultar comprender cabalmente tanto el cambio histórico como el cambio historiográfico vividos. En el siglo XXI, desvelado el gran secreto de que la historia la hacemos los historiadores, alentamos, junto con la reflexión y la historiografía, la escritura de autobiografías de historiadores $^{74}$ para comprender mejor la historia que se escribe, como forma de hacer más transparentes los valores que para bien y para mal (más lo primero que lo segundo) el historiador aporta a su obra, en línea con nuestra opción por un nuevo concepto de la historia como una ciencia con sujeto cognoscente.

Por otro lado, siempre será más fácil hacer una historiografía de valores que una política de valores. Yo quiero ser compasivo con los políticos que tenemos, porque creemos en la democracia, que no nos salió gratis, aunque nos gustaría que asumieran de verdad una democracia con nuevas dimensiones éticas y participativas. No puede ser que los políticos que nos representan electoralmente estén, paradójicamente, a la cola de la estimación de la sociedad. Quienes nos gobiernan, o nos pueden gobernar, tienen muy difícil al parecer ser coherentes en sus prácticas con los principios que

\footnotetext{
${ }^{72}$ Otra cosa es que cuarenta años después se pretenda idealizar una democracia que nació en medio de grandes dificultades - bajo la bota militar - y fue perdiendo con el paso de los años calidad y memoria sobre sus condiciones originales.

${ }^{73}$ La autonomía intelectual que practicamos y propugnamos en Historia a Debate se opone a la vieja "historia militante", y va más allá incluso del concepto gramsciano del historiador como "intelectual orgánico" respecto de las clases y grupos sociales, en las antípodas de todos modos de la historia académica presuntamente aséptica de los viejos y nuevos positivistas, estrategia de camuflaje de los propios compromisos.

${ }^{74}$ Un buen precedente, que no tuvo continuidad, fueron los trabajos reunidos por el prolífero NORA, Pierre. Essais d'ego-histoire. París: Gallimard, 1987 (Collection Bibliothèque des Histoires); hemos incluido en este IV Congreso de $\mathrm{HaD}$ (2010) una mesa redonda con el título "El historiador de sí mismo".
} 
declaran. El poder de internet como medio democrático, horizontal y transnacional de comunicación está contribuyendo grandemente con el sacrificio de algunos a ponerlo en evidencia. Es como cuando en un acto queda encendido inadvertidamente el micrófono y nos enteramos de los comentarios que hacen los que presiden la mesa. Gracias a internet nunca supimos tanto sobre la doble moral de nuestros representantes públicos. Si a ello unimos el movimiento social de indignación surgido en 2011, coordinado asimismo en internet, concluimos que en este nuevo siglo a los políticos profesionales les está resultando más complicado que nunca ser coherentes y honrados. De ahí la descomunal "crisis de la política" (representativa) que vivimos. Evitemos que la historia siga el mismo camino separando falsamente historiadores y ciudadanos. ${ }^{75} \mathrm{Al}$ no entrañar nuestro oficio una posición de poder político o económico, siempre será más sencillo, luego, hacer una historiografía de valores que una política de valores, por lo que podemos y debemos dar ejemplo de compromiso, ética y coherencia, comenzando por contar la verdad de la historia que conocemos, caiga quien caiga.

\section{Valores profesionales y sociales}

Los nuevos valores históricos e historiográficos de los que hablamos no constituyen, obviamente, una propuesta ex novo, tienen un origen histórico y guían ya de modo más o menos explícito la parte más inquieta, humanista y optimista de la comunidad internacional de historiadores dentro y fuera de Historia a Debate y del ámbito académico latino.

¿Qué valores consideramos significativos para la historia, la universidad y la sociedad de nuestro tiempo? Lo primero es discernir entre valores profesionales y no profesionales, inseparables por descontado: los primeros han de interactuar y evolucionar con los segundos, no son atemporales. La realidad del siglo XXI global espacialmente, conlleva también una interconectada "totalidad", como decían de su objeto las vanguardias del siglo que pasó. No podemos concebir en la nueva sociedad de la información una deontología profesional al margen de una ética social, civil y global avanzada. Son los grandes valores sociales, políticos, económicos y culturales tendencialmente mayoritarios que informan el nuevo derecho jurídico internacio-

\footnotetext{
${ }^{75}$ Solamente justificable desde un retornado objetivismo positivista.
} 
nal, ${ }^{76}$ los han de orientar e ilustrar los valores profesionales de la historia y demás disciplinas académicas, así lo reivindican - junto con la opinión pública global - los investigadores en las áreas o temáticas de trabajo científicamente más punteras, polémicas y actuales: la historia no puede quedar atrás aferrada al árbol seco de un empirismo decimonónico.

Siguiendo a las ciencias más adelantadas somos cada vez más los historiadores que entendemos la separación entre el objeto y el sujeto del conocimiento histórico como un constructo imaginario, obstáculo epistemológico que nos distancia de nuestro tiempo al pretender convertir en absolutas las verdades históricas de la academia. Por eso hemos redefinido la historia como una ciencia con sujeto cognoscente en el primer punto del Manifiesto Historiográfico de Historia a Debate (2001), ${ }^{77}$ equiparando el investigador y su objeto, el historiador y sus fuentes, ${ }^{78}$ como factores igualmente determinantes de la generación del conocimiento histórico desde cada presente. Rechazando tanto el cisma sujeto / objeto del positivismo (el historiador "desaparece" cuando investiga) como del posmodernismo (el historiador "inventa" la historia).

Nada mejor que el concepto de paradigma para expresar esta unión dialéctica e igualitaria entre el objeto y el sujeto, las fuentes y los valores, en la historia que escribimos. Define Kuhn 'paradigma' como conjunto de "creencias, valores, técnicas (...) compartidos por los miembros de una comunidad dada" de especialistas. ${ }^{79}$ Valores (creencias estables) tanto profesionales (elementos de metodología, historiografía, teoría, relación con la sociedad) como no profesionales (éticos, sociales, religiosos y políticos). Concepto no positivista de la ciencia que pone en evidencia que es la comunidad de historiadores quien decide en última instancia la verdad (consensuada de un modo u otro) sobre los resultados de las investigaciones: verdades históricas que van surgiendo de las interacciones historiadores-fuentes. La empiria está, se acepte o no, provechosamente condicionada por los investigadores, sus capacidades intelectuales y profesionales, sus valores historiográficos (selección de temas, métodos y enfoques) y sus mentalidades sociales carac-

\footnotetext{
${ }_{76}$ Nos referimos a Occidente cuyos valores de origen ilustrado se extienden por todo el mundo de manera paradójica: generan movimientos sociales que cuestionan por su doblez a su gobernanza y la economía global de mercado.

77 Véase una primera formulación en el apartado 4, sobre la redefinición de la historia como ciencia y la nueva física, de La historia que viene. Historia a debate. I. Pasado y futuro. Santiago: Historia a Debate, 1995, p. 95-117 (www.h-debate.com/cbarros/spanish/historia_que\%20viene.htm).

${ }^{78}$ El historiador y sus fuentes (2010). En: https://www.youtube.com/watch?v=iyBz_dlMgf8.

${ }^{79}$ KUHN, Thomas S.La estructura de las revoluciones científicas. México, 1975 (ed. original en inglés, 1962), p. 269.
} 
terísticas de cada época. ${ }^{80}$ Una historia objetiva/subjetiva que se acerca más a la realidad cotidiana del trabajo de los investigadores que las ingenuas definiciones "científicas" precedentes. ${ }^{81}$ Nuevo concepto de la historia como ciencia que venimos ejercitando desde hace 20 años como primer valor metodológico y epistemológico. Actúa como la clave de bóveda de Historia a Debate como plataforma y tendencia historiográfica, nos ha permitido relacionar las partes académicas y no académicas de los valores historiográficos. Ciencia con sujeto que nos exige ubicar en el centro de nuestra historiografía de valores la búsqueda de una verdad histórica, a menudo plural, poliédrica, siempre realista y social.

Sobre cómo enfocar los valores historiográficos no profesionales, partimos de dos premisas: a) el funcionamiento real de las comunidades científicas, según la historia de la ciencia posterior a Popper, b) la materia humana sensible sobre la trabajamos los historiadores, y en general las humanidades y las ciencias sociales. Lo que nos obliga, en mayor medida que a las ciencias de la naturaleza, ${ }^{82}$ a asumir valores sociales y políticos que - justo es reconocerlo - han hecho posible la constitución, evolución y renovación de la historia como ciencia a lo largo de los siglos XIX y XX. Historiografía y contexto: el positivismo no hubiera existido sin el Estado-nación; tampoco las nuevas historias del marxismo y Annales sin los movimientos sociales, el auge económico y el Estado de Bienestar de la posguerra. En este siglo XXI, el estatus académico y público, la unidad y el futuro de la historia como disciplina científico-social depende sin lugar a dudas de cuánto progresen los nuevos movimientos sociales y la globalización alternativa, humanizadora, ${ }^{83}$ a la que tratamos de contribuir con una historia actualizada que tome como referencia los valores y derechos de los hombres, de las mujeres y del medio ambiente, ${ }^{84}$ por encima de ideologías, naciones y religiones. Sin una globalización más humana y social, y menos financiera y economicista, mal podremos desarrollar las ciencias humanas. Podemos ciertamente tratar

\footnotetext{
${ }^{80}$ Se dice justamente que la literatura retrata una época, de alguna forma se podría decir lo mismo de la escritura de la historia, que investiga el pasado con la pericia y los ojos de cada presente.

${ }^{81}$ BARROS, Carlos. Por un nuevo concepto de la historia como ciencia (2005). En: https://youtu. be/f_41qV42A1I.

${ }^{82}$ También las "ciencias duras" necesitan hoy una deontología ético-social si quieren promover y defender el avance de sus investigaciones, en asuntos de interés social y humano, frente a intereses económicos y políticos minoritarios pero muy poderosos.

${ }^{83} \mathrm{BLOCH}$, Marc. El objeto de la historia es esencialmente el hombre, mejor dicho los hombres. In: Idem. Introducción a la historia. México: Fondo de Cultura Económica, p. 24-25.

${ }^{84}$ Ver: Por un nuevo concepto de la historia como ciencia, loc. cit.
} 
nuestro objeto de investigación como si fuera una cosa, ya se ha hecho, con resultados a la larga funestos por parte del positivismo (ni siquiera las enaltecidas "grandes figuras" fueron tratadas humanamente), el economicismo y el estructuralismo. Toca ahora re-humanizar la historia si queremos que el mundo actual entienda la utilidad académica, científica y social de lo que hacemos los historiadores.

No sobra recordar al presente que los valores humanos de referencia universal, inclusive judicialmente, son fruto de un proceso histórico cuyo hilo conductor parte de la Ilustración, ${ }^{85}$ con sus grandes aciertos y errores, hasta sus reformulaciones actuales ${ }^{86}$ en un ámbito históricamente inédito, global (no sólo internacional), superador del eurocentrismo y la frustrada experiencia de un nuevo Imperio americano. ${ }^{87}$ Valores globales que han nacido, caído y resucitado una y otra vez en dura lucha (que ha costado innumerables vidas) contra otros "valores" que no solemos considerar tales, pese a implicar también "creencias estables", como el militarismo, el totalitarismo, el racismo, el fundamentalismo y el terrorismo. Valores pacíficos y democráticos que venimos enseñando en la escuela y cultivando, cada vez menos minoritariamente, en la universidad desde hace décadas. Derechos humanos que afrontan en su aplicación resistencias fácticas políticas ${ }^{88}$ sociales y culturales, así como diversidad de interpretaciones ${ }^{89}$ cuando entran en juego los

\footnotetext{
${ }^{85}$ La Ilustración no sólo predicó, también dio trigo, contribuyó a desencadenar procesos históricos concretos (políticos, sociales e intelectuales) enlazados entre sí (Revolución francesa, movimiento obrero y marxismo, descolonización, feminismo y ecologismo) y dio origen a las ciencias humanas y sociales (LÉVI-STRAUSS, Claude. Antropología estructural. México: Paidos Iberica, 1987, p. 37, 273).

86 "Las comunidades de historiadores han de contribuir pues a construir una 'nueva Ilustración' que, aprendiendo de los errores de la historia y de la filosofía, piense teóricamente el sentido del progreso que hoy demanda la sociedad todos los días, asegurando a las grandes mayorías del Norte y del Sur, del Este y Oeste, el disfrute humano y ecológico de los avances revolucionarios de la medicina, la biología, la tecnología y las comunicaciones". Punto XIV del Manifiesto de HaD.

${ }^{87}$ Tratamos sobre el Project for the New American Century de George W. Busch en: Historia a Debate, un paradigma global para la escritura de la historia. Historia a debate. I. Reconstrucción. Santiago: Historia a Debate, 2009, p. 133-156. (http://www.h-debate.com/cbarros/spanish/ articulos/nuevo_paradigma/Paradigmaglobal.htm); si buscamos ahora el PNAC en la web nos encontramos con el mensaje "this account has been suspended": más gráfico imposible.

${ }^{88}$ Sería el caso de las negativas de los Estados Unidos a reconocer el Tribunal Penal de La Haya o el Protocolo de Kioto, o del Estado español a juzgar a los responsables de los crímenes franquistas como exige la ONU.

${ }^{89}$ Un ejemplo perturbador de historia inmediata: el movimiento social y global de los indignados (2011, Túnez-2013, São Paulo) triunfó gracias a su pacifismo, sin embargo las circunstancias les llevaron a tomar las armas en Libia y Siria, siendo sobrepasados (sobre todo en el segundo caso) por Al Qaeda y el fundamentalismo islámico.
} 
intereses del poder y de la economía, o cuando lo individual (ideología, identidad, religión) entra en colisión con los valores hoy universalmente asumidos. ${ }^{90}$ Queremos decir que los valores están continuamente a debate cuando abandonan la dimensión abstracta. Ahí es donde podemos y debemos colaborar con nuestra mirada histórica, sin campos vedados, incluyendo el debate sobre el género, la familia y la sexualidad que afecta a la Iglesia católica.91

La historia sólo puede estar en el siglo XXI del lado de esta globalidad alternativa que reivindica y trata de llevar a la práctica valores de paz, solidaridad y justicia, igualdad y libertad, educación y salud, ecología y género, defendiendo y promoviendo a las víctimas de los agresores, a los sectores menos favorecidos y discriminados de la sociedad - la mayoría social - de la corrupción y los abusos del poder. Auctoritas y objetividad del proceso globalizador (en su dimensión no economicista) que hace que los grandes valores se cuelen por todos los intersticios ${ }^{92}$ (lugares, regímenes y culturas) engendrando primero las ONGs planetarias y después movimientos sociales críticos con el poder económico multinacional, desde el altermundismo a los indignados, en continua lucha por una democracia plena, igualitaria y global. ${ }^{93}$ Nuestro mundo académico e historiográfico no tiene futuro al margen de esta globalidad social y solidaria, con rostro humano, en marcha.

\section{Academia solidaria}

La historiografía de valores ha de empezar por nosotros mismos. En el año 2000 iniciamos en Historia a Debate un nuevo tipo de actividad, que denominamos Academia Solidaria, en protesta por una intervención policial en la Universidad Nacional Autónoma de México y el asesinato por ETA

\footnotetext{
${ }^{90}$ Es menester aclarar, con todo, que el derecho a una ideología, identidad etno-nacional o creencia religiosa está amparado por el valor de las libertades... siempre que no perjudique o suponga opresión sobre terceros.

${ }^{91}$ La elección en 2013 del papa Francisco, que aboga desde el Vaticano por los grandes valores sociales, económicos y políticos está creando nuevas condiciones para el diálogo, dentro y fuera de la Iglesia, sobre temas como la pederastia, el aborto, el divorcio y la homosexualidad.

${ }^{92}$ La eficacia, empuje y generalización de los derechos humanos, viejos y nuevos, es consecuencia de la interacción entre una sociedad civil global culta, intercomunicada y cada vez más exigente con instancias internacionales como la ONU, la Unesco y los tribunales internacionales que aportan legitimidad jurídica y global en una tesitura en que los viejos Estados democráticos y no democráticos siguen jugando frecuentemente a la contra.

${ }^{93}$ BARROS, Carlos. Historia inmediata: de Chiapas a los indignados. Conferencia inaugural del XXVII Congreso Internacional Historia Regional / VII Encuentro de Historiadores de Sinaloa. Culiacán, 8 de diciembre de 2011 (http://www.youtube.com/watch?v=bHqkczWoBwE).
} 
del historiador y político socialista Ernest Lluch. ${ }^{94}$ Hemos continuado estos últimos 14 años denunciando, recogiendo firmas y amparando a colegas en cualquier lugar del mundo que sufran represión ${ }^{95} \mathrm{o}$ amenazas en el ejercicio de su profesión como investigadores y docentes, también como ciudadanos. ${ }^{96}$ Sucede a menudo que en contextos de conflictos, revueltas o guerras, los historiadores y otros académicos objetos de represalias pasan desapercibidos en el conjunto de las víctimas: si sus compañeros de profesión no denunciamos estos casos serían reprimidos con más facilidad. ${ }^{97}$

Para nuestra tarea solidaria hemos tenido por lo regular apoyos más que suficientes, pero también resistencias y muchos nos sabe / no contesta: la solidaridad tampoco es un uso académico. ${ }^{98}$ A causa del peso en nuestro medio del individualismo, la competitividad y la fragmentación, escasamente contrarrestados por asociaciones transversales de tipo académico-profesional que raramente se pronuncian acerca de cuestiones "ajenas" a su especialización académica. No existe por consiguiente una tradición académica de solidaridad inter-personal, nos distinguimos en esto del resto de la sociedad, una muestra más de orden gremial de la brecha persistente entre academia y sociedad civil.

Pero la horizontalidad de internet está cambiando el statu quo: la nueva sociabilidad académica que representa Historia a Debate ${ }^{99}$ nos ha permitido ir más allá del corporativismo académico, captando el signo solidario de

\footnotetext{
${ }^{94}$ Academia Solidaria de Historia a Debate (http://h-debate.com/academia-solidaria-2/).

${ }^{95}$ Resulta significativo que no hubiera surgido algo semejante, fuera del ámbito académico latino, ante la abundancia de casos de historiadores represaliados en el siglo XX, véase el diccionario de historiados represaliados de BAETS, Antoon. Censorship of historical thought, a world guide, 1945-2000. Westport, Connecticut: Greenwood Publishing Group, 2002; nuestro colega holandés viene recolectando, desde 1995, casos de historiadores denunciados por Amnistía Internacional (http://www.concernedhistorians.org/content/home.html).

${ }^{96}$ También hemos activado nuestra solidaridad en situaciones donde la historiografía o la universidad estaban en cuestión, o simplemente estaban en juego valores humanos importantes (guerra, terrorismo, problemas sociales).

${ }^{97}$ Justo es reconocer que el sector profesional que más cuida la solidaridad entre sus miembros (no confundir con corporativismo como demanda y defensa de privilegios) son los periodistas, tal vez la profesión más castigada por regímenes autoritarios y señores de la guerra, por el poder en su conjunto.

${ }^{98}$ Hemos dicho lo mismo hace 20 años sobre los debates cuando empezamos con HaD y ahora se puede decir que "el debate es un uso académico", al menos en el ámbito de influencia de nuestra red / movimiento historiográfico internacional.

${ }^{99}$ BARROS, Carlos. La sociabilidad académica en la era global. Seminario de Posgrado en la Universidad de Santiago de Compostela, 2007 (http://h-debate.com/wp-content/uploads/2015/ audio/La-Sociabilidad-Academica-En-La-Era-Global-A-(-31107)-Carlos-Barros.mp3).
} 
los tiempos que vivimos y la emergencia de nuevas formas de compromiso académico, dirigidas tanto al exterior como al interior de nuestro campo de estudio y trabajo.

El último caso de Academia Solidaria que hemos tratado en $\mathrm{HaD}$ es la solidaridad con los historiadores catalanes que han organizado en diciembre de 2013 el congreso "España contra Cataluña. Una mirada histórica, 1714-2014", inaugurado en plena borrasca por el historiador-ciudadano Josep Fontana. Frente a otros historiadores españoles que, lícitamente, han aprovechado para confrontar, desde El País, ABC y otros medios tradicionales de comunicación, su compromiso españolista con el catalanismo de los participantes, hemos levantado como Academia Solidaria la voz ${ }^{100}$ contra la denuncia que los partidos políticos PP, UPyD y Ciudadanos presentaron contra los colegas organizadores y participantes por "incitar al odio" (!), delito insertado en el Código Penal para combatir el racismo, el neonazismo y el fascismo. ${ }^{101}$ La Fiscalía archivó finalmente la querella, pero el solo hecho del plantearse puso en evidencia que alguien pensó en "dar ejemplo" frente al independentismo catalán reprimiendo a los historiadores catalanistas. Un ejemplo, en cualquier caso, de la diferencia que establecemos entre los libres compromisos de partido o ideológicos de los historiadores, que suelen influir consciente e inconscientemente en su obra (no necesariamente para mal), y una historiografía de valores más general y explícita, que no debería contradecir compromisos más parciales e implícitos, pero lo hace. ${ }^{102}$ En resumen, para que el pensamiento crítico sea completo, es decir autocrítico, ha de integrar la autonomía política, ideológica y religiosa del historiador, cuando no la independencia si su "dependencia orgánica" obstaculiza el despliegue de su historiografía de valores.

\footnotetext{
${ }^{100} \mathrm{HaD}$ con los historiadores catalanes: http://h-debate.com/con-los-historiadores-catalanes-131213/.

101 Todos los partidos representados en el Congreso de Diputados, menos el PP, estuvieron de acuerdo el 17 de octubre de 2013 en añadir al Código Penal la exaltación del franquismo: habrá que esperar a que quienes hoy están en la oposición defiendan lo mismo en el futuro si alcanzan el Gobierno.

${ }^{102}$ El mejor servicio que el intelectual puede prestar a "los suyos" es ser fiel a la universalidad de los valores que se dicen defender, aunque sólo fuera por eficacia: en la sociedad de la información se hace más difícil la manipulación; ejemplos negativos del siglo XX son el silencio crítico de los intelectuales occidentales durante la II Guerra Mundial hacia las bombas atómicas de Hiroshima y Nagasaki y la pasividad de muchos intelectuales de izquierda hacia los crímenes del estalinismo.
} 


\section{¿Puede o debe el historiador justificar la esclavitud?}

En el punto VIII del Manifiesto de HaD hablamos de la necesaria autonomía del historiador frente a los poderes establecidos de tipo político, económico, editorial o mediático: ${ }^{103}$ sólo se puede implementar desde una historiografía de valores profesionales y no profesionales. ${ }^{104}$ Lo contrario sería gremialismo, como cuando se critica soberbiamente tal o cual uso político y público (externo) de la historia, ocultando el uso más o menos público y político que hace el propio historiador con sus posiciones y publicaciones, se quiera o no. Dicho de otro modo, de lo que no ha de ser autónomo el profesional cabal de la historia es de los valores y derechos que sustentan la voluntad general en marcha de un ordenamiento cultural, social y político más justo, libre y humano. Cuya puesta en práctica no es por descontado unívoca, ni política ni historiográficamente, ha de estar continuamente en debate. ¿Si renunciamos dentro de la academia a la pluralidad que teóricamente defendemos fuera, qué nos queda? ${ }^{105}$

La historiografía de valores plantea otro reto: el ejercicio de la responsabilidad por parte del historiador cuando investiga, enseña y difunde sus trabajos. Una manera corriente de eludirla es negar otra autonomía profesional no menos obligatoria: la del historiador respecto de las fuentes, ${ }^{106}$ cuya idolatría convertiría los resultados de nuestras investigaciones en una "verdad revelada". Ni siquiera los historiadores más enclaustrados académicamente son inmunes a una utilización externa de sus pesquisas. No hay otra, tenemos que ser proactivos y empáticos cuando tratamos sobre temas históricos de interés público: aceptando la posibilidad de errar y que la historia académica, por muy bien documentada que esté, no es "palabra de

\footnotetext{
103 "Contra la razón mercantil de las grandes editoriales y medios de comunicación social", decíamos en la conferencia El compromiso del historiador, hoy. In: La historia de la historiografía contemporánea en España, curso organizado por la Institución Fernando el Católico y la Universidad de Zaragoza. Zaragoza: Universidad de Zaragoza, diciembre de 1998.

${ }^{104}$ Lo no profesional es lo que nos salva de caer en el academicismo.

${ }^{105}$ Si nos preguntamos si es compatible el consenso académico con la pluralidad, la autonomía individual con la responsabilidad colectiva, la respuesta es afirmativo, la experiencia de Historia a Debate lo demuestra., BARROS, Carlos. Historia a Debate, un paradigma global para la escritura de la historia. Historia a debate. I. Reconstrucción. Santiago: Historia a Debate, 2009, p. 133-156. (http://www.h-debate.com/cbarros/spanish/articulos/nuevo_paradigma/Paradigmaglobal.htm).

${ }^{106}$ BARROS, Carlos. El historiador y sus fuentes (2010). En: https://www.youtube.com/watch?$\mathrm{v}=\mathrm{iyBz} \_\mathrm{dlMgf8}$.
} 
Dios", está condicionada por el investigador como toda ciencia que se precie. Nos perjudican a todos, quienes digan lo contrario demandando subrepticiamente ${ }^{107}$ un "monopolio" del historiador sobre la escritura de la historia. Cada generación quiere, y está en su derecho como sujeto histórico y/o sujeto académico, reescribir la historia; y cada cambio social y político, cultural o ideológico, incide sobre la historia que se escribe. Nuestra credibilidad como profesionales es anticiparnos y contribuir al cambio histórico-historiográfico más deseable desde el punto de vista del progreso, de una mejor historia y valores. Dejarse llevar por la marea, o mostrarse ajeno al siglo, ni es inteligente ni es responsable, aunque sea involuntario, afecta a la disciplina de la historia, también a la historia extra académica.

Acostumbro a poner como ejemplo coetáneo de la responsabilidad o irresponsabilidad del historiador, y de los buenos y malos valores historiográficos, el caso del colega francés que sirvió de pretexto para el último giro positivista de la historiografía francesa encabezado por Pierre Nora, en 2005, y su asociación Liberté pour l'histoire contraria a la memoria histórica. Olivier Pétré-Grenouilleau, profesor de historia en el conservador Institut d'études politiques de París, defiende en Les traites négrières. Essai d'histoire globale (París, 2004) que el tráfico de esclavos hacia Europa durante el Antiguo Régimen no tuvo "carácter genocida", ${ }^{108}$ ni siquiera implicó violenta opresión, dado que los negreros no tuvieron intención criminal hacia ellos y sí un interés puramente mercantil. ${ }^{109}$ Proclamando que la esclavitud fue consecuencia de la estructura económica de la época: ${ }^{110}$ el historiador no debe juzgar ni tomar

\footnotetext{
${ }_{107}$ No es el caso de Pierre Nora que lo hace abiertamente, lo que le honra, por mucho que lamentemos su radical oposición a la memoria histórica. BARROS, Carlos. Historia, memoria y franquismo. Historia Actual Online, no 33, Cádiz, 2014, p. 153-171 (http://www.historia-actual. org/Publicaciones/index.php/haol/article/viewFile/976/891).

${ }^{108}$ En sentido contrario, referido al Caribe africano, otros historiadores más sensibles a la humanidad de su objeto, los esclavos y sus derechos históricos a la justicia, la verdad y la reparación. BECKLES, Hilary McD. Britain's black debt: reparations for Caribbean slavery and native genocide. Kingston: University of the West Indies Press, 2013.

${ }^{109}$ Es decir que los tratantes preferían a los esclavos vivos y sanos, defiende el autor: en realidad les sobraba mano de obra, mataban a los rebeldes para meter miedo al resto, ahorraban en manutención y alargaban la jornada de trabajo para incrementar los beneficios, además del delito de lesa humanidad que suponía y supone quitarle la libertad a un hombre o mujer de por vida.

110 Algunos colegas valoran lo bueno que aportaron el economicismo y el estructuralismo para las ciencias sociales del siglo $\mathrm{XX}$, pero nada dicen de los efectos catastróficos de haber restringido, si no eliminado, el papel del sujeto humano y social de la historia: "el fin último de las ciencias humanas no es constituir al hombre, sino disolverlo". LEVÍ-STRAUSS, Claude. El pensamiento salvaje. México: Fondo de Cultura Económico, 1964, p. 357.
} 
partido, viene a decir "asépticamente" el autor, justificando objetivamente la esclavitud en la historia. No creo que el investigador en su cubículo previera el temporal que iba a desatar, tampoco que quisiese ofender en plan racista a los afro-franceses (en definitiva, se trataba de un trabajo académico), más bien actuó de manera irresponsable, mostrando cierta incomprensión del mundo actual y sus valores emergentes. De hecho su obra será recordada ${ }^{111}$ por la polémica engendrada, no por sus aportes historiográficos que los tiene, como su enfoque de historia global. No advirtió Pétré-Grenouilleau que los descendientes de aquellos esclavos son, en este nuevo siglo, parte memorial y políticamente activa de la democracia francesa, con el sostén de las instituciones republicanas y la opinión pública de la gente. Conocido el libro y su reaccionaria tesis el Collectif des Antillais, Guyanais, Réunionnais et Mahorais ${ }^{112}$ presentó una denuncia judicial contra nuestro colega por apología de la esclavitud, en base a la declaración de la Asamblea legislativa francesa de la esclavitud como crimen contra la humanidad (2001) gracias al voto favorable de todos los partidos menos la extrema derecha del Front National.

Una historiografía de valores tiene que defender, sin asomo de duda alguno, la historia como una disciplina libremente ejercida ${ }^{113}$ y oponerse, en consecuencia, a cualquiera penalización del historiador académico, tenga la ideología que tenga. ${ }^{114}$ Así debieron de concluir, juiciosamente, los descendientes de los esclavos cuando retiraron la denuncia contra el historiador francés, una vez publicitada - todo hay que decirlo - su reivindicación de una verdad histórica que el libro, y quienes lo sustentan, niegan a sus ascendientes, al tiempo que le es reconocida por la ONU, el derecho internacional y las leyes francesas. Cara al futuro, la lección es clara: si quieres interpretar la pérdida de libertad y la explotación de los esclavos como algo estructural e históricamente "inevitable", hasta benéfico para la economía del aquel momento, hazlo abiertamente en el marco del debate subsiguiente, historiográfico y político (el tema es obviamente de interés público), sin escudarse en una supuesta neutralidad o "superioridad" académica. La historia

\footnotetext{
111 Pese a los premios de consolación que le dieron a la obra pro-esclavista instituciones conservadoras como la Académie Française.

112 Web del grupo memorial antillano: https://collectifdom.wordpress.com/.

113 El límite de la libertad es no perjudicar a terceros, como hacen (pensamos que inocentemente) PétréGrenouilleau y, de forma más general, Pierre Nora y Liberté pour l'histoire, según vimos y veremos.

${ }^{114}$ Salvo posiciones totalitarias que amenacen frontalmente (neonazismo, neofascismo, racismo; véase la nota 99) la democracia y la sociedad: no parece el caso del autor de Les traites négrières.
} 
ha de estar permanentemente a debate, dentro y fuera de la universidad, lo contrario infringe un daño a nuestra profesión y su credibilidad en amplios sectores de una sociedad que paga nuestros salarios: el caso que nos ocupa es ilustrativo al respecto.

Aprovechando que el Pisuerga pasa por Valladolid, Pierre Nora, historiador de mil batallas no pocas reseñables y favorables para la historia, sin decir nada curiosamente del desdichado caso de Pétré-Grenouilleau hace un llamamiento el 13 de diciembre de $2005^{115}$ reivindicando una suerte de "historia para los historiadores" así como diversas consignas publicitarias como "L'histoire n'est pas la morale", "L'histoire n'est pas la mémoire", a fin de conseguir (sin éxito alguno, ciertamente) ${ }^{116}$ la abrogación de las leyes memoriales de la República francesa. ${ }^{117}$ Eso sí, dicha iniciativa harto corporativa de Nora y seguidores logró marcar, abanderar e impulsar el largamente anunciado ${ }^{118}$ giro conservador iniciado en los años $1980,{ }^{119}$ de la historiografía en Francia, a costa de agrandar la brecha entre la historia académica y la sociedad francesa y sus actores políticos (menos la extrema derecha de Jean-Marie y Marine Le Pen, significativamente).

\section{¿Rigor sin valor?}

La historia no puede ser rigurosa si no es honesta, y viceversa, entendiendo la honestidad tanto individual como colectivamente, ética y socialmente. No suele decirse esto cuando se enseña el "método científico" de la historia, desde un concepto positivista y neopositivista de la historia. El método hipotético deductivo y el cuantitativismo aportados a los nuevos

\footnotetext{
${ }^{115}$ Manifiesto que ha dado lugar según dijimos a la formación de una asociación denominada Liberté pour l'histoire (http://www.lph-asso.fr/), que consecuente con su conservadurismo y doble rasero negó en 2010 apoyar al juez Garzón, como pedía Bertolomé Bennassar, en sus pretensiones de justicia, verdad y reparación para las víctimas del franquismo. BARROS, Carlos. Historia, memoria y franquismo (2013). En: http://www.h-debate.com/cbarros/spanish/ articulos/memoria/Historia_memoria_y_franquismo.htm.

${ }^{116}$ La opinión pública francesa es obvia y manifiestamente favorable a las lois mémorielles.

117 A diferencia de la Ley española de la Memoria Histórica (2007) Francia penaliza, siguiendo a los alemanes, las opiniones contrarias a las leyes memoriales (progresistas en su mayoría) sin que tengan que actuar los tribunales, al menos que sepamos.

118 BARROS, Carlos. La "Nouvelle Histoire" y sus críticos. Manuscrits. Revista d'Història Moderna, $\mathrm{n}^{\circ}$ 9, Barcelona, 1991, p. 83-111 (www.h-debate.com/cbarros/spanish/nouvelle.htm).

119 El fracaso del tournant critique de 1989 (http://www.h-debate.com/cbarros/spanish/tournant.htm) entraña la dilución final de Annales como tendencia historiográfica, abriendo el camino a la restauración del positivismo en la patria de Marc Bloch, Lucien Febvre, Fernand Braudel y Jacques Le Goff.
} 
historiadores por el neopositivismo, en los años 1960 y 1970, no alteró la base epistemológica de Ranke, Langlois y Seignobos, tampoco lo hicieron Annales y el materialismo histórico cuando validaban de alguna forma el objetivismo positivista en flagrante contradicción con sus contribuciones más revolucionarias. ${ }^{120}$ Hoy sabemos positivamente que una ciencia que no tenga en cuenta la subjetividad historiográfica no es, ni puede ser, una ciencia verdadera sino puro cientifismo. La historia ha llegado con un gran retraso a la "ciencia con conciencia" que empieza por el respeto ${ }^{121}$ hacia los protagonistas de la historia y las fuentes que engendraron, pese a su común parcialidad. Una ciencia unida a la ética es, en la actualidad, imprescindible para sostener y propagar la verdad de la historia que vamos conociendo, sujeta en ocasiones a dilemas morales e incomodidades que el historiador riguroso ha de ser capaz de arrostrar con valores... y con valor.

El valor tampoco es un uso académico, lo sabemos. ${ }^{122}$ Voy a poner un ejemplo (extremo, por lo tanto didáctico) que muestra cómo, en algunos temas, no hay verdad histórica al margen del "valor"123 y de los "valores" del historiador. Singular y plural interdependientes que se transforman en épica al fusionarse. Hay circunstancias que obligan al historiador o a los historiadores con rostro humano a actuar valerosamente en defensa de la verdad histórica. A veces, investigar y divulgar la verdad histórica requiere peligros reales e imaginarios que se salen de lo habitual académicamente, en contextos autoritarios pero también democráticos, donde no siempre está garantizado el ejercicio libre de la investigación histórica. ${ }^{24}$ Diferenciamos la investigación de materias que pueden "molestar" a tal o cual ideología, religión o poder fáctico, de lo que huyen preventivamente muchos historiadores para eludir la controversia aun siendo temas de interés historiográfi-

\footnotetext{
${ }^{120}$ Sobre la continuidad de la epistemología objetivista en la historiografía del siglo XX, ver Por un nuevo concepto de la historia como ciencia (2005) en: https://youtu.be/f_41qV42A1I.

${ }^{121}$ Ciertamente, una cosa es el respeto hacia las fuentes y otra bien distinta su ciega adoración, valor negativo donde los haya, como denunció Marc Bloch.

${ }^{122}$ Me refiero a las carreras académicas en tiempos democráticos: el comportamiento de los universitarios (jóvenes, sobre todo) en situaciones de dictadura, guerra u ocupación está históricamente demostrado que puede ser tanto o más valeroso que otros sectores de la sociedad.

${ }^{125}$ Identificando los "deberes" con "valores" (autoconciencia), cambiando "ciudadanía" y "cívico" por "historiografía" e "historiográfico" podemos definir el valor del historiador como "entereza de ánimo para cumplir los deberes de la historiografía, sin arredrarse por amenazas, peligros ni vejámenes" (DRAE, 22 $2^{\mathrm{a}}$ edición, 2001).

${ }^{124}$ Los informes de las instituciones internacionales son claros, respecto a la baja calidad de la democracia en el mundo de hoy.
} 
$\mathrm{Co}^{125}$ de otros objetos de investigación que pueden conducir a una denuncia penal o algo peor ${ }^{126}$ de parte de quienes detentan el poder ${ }^{127}$ o lo detentaron en el pasado:128 nuestro mejor y más cercano ejemplo es el franquismo y sus secuelas en la España del siglo XXI.

A pesar de los 37 años transcurridos desde la transición, los investigadores de la represión franquista y la memoria histórica siguen autocensurándose, salvo raras excepciones, a la hora de identificar o simplemente nombrar los represores del régimen, responsables directos y/o intelectuales de las 150.000 desapariciones documentadas a partir de 1936, como parte de la "limpieza ideológica" llevada a cabo por el bando ganador. La continuidad hasta hoy del miedo académico ${ }^{129}$ a decir la verdad completa ${ }^{130}$ sobre la dictadura, inclusive cuando la ley del silencio se va disipando ${ }^{131}$ en pueblos y ciudades, constituye una prueba más de la supervivencia del franquismo en la España actual, que viene lastrando desde la transición la calidad, el desarrollo y el prestigio de la democracia española, inferior en este aspecto cru-

\footnotetext{
${ }^{125}$ Es el caso del derecho de pernada en la Edad Media, que implica también a los señores eclesiásticos, vez investigadas las fuentes, descubrí con sorpresa la ausencia de antecedentes bibliográficos por causa de los temores y prejuicios vivos en el medievalismo; BARROS, Carlos. Rito y violación: derecho de pernada en la Baja Edad Media. Historia Social, $\mathrm{n}^{\circ} 16$, Valencia, primavera-verano 1993, p. 3-17 (http://www.h-debate.com/cbarros/spanish/pernada_castellano.htm).

${ }^{126}$ En contextos políticos mediatizados por la violencia hay estudiosos se juegan la vida como Darío Betancourt, historiador de la violencia en Colombia desde los años 1950 al presente, asesinado en 1999 (http://yquepasoconlosdesaparecidos.blogspot.com.es/2008/06/universidad-pedagogica-nacional.html); en el mismo año y país sufrió el mismo destino el historiador Jesús Antonio

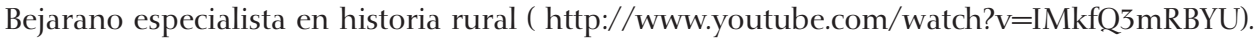

${ }^{127}$ Como la citada denuncia del partido del Gobierno contra los historiadores catalanistas por el congreso de diciembre de 2013 por investigar y dar a conocer la conflictividad histórica entre España y Cataluña, que pasó así de un tema histórico simplemente incómodo a motivo causa de persecución "legal" por "incitación al odio" con la intención de amedrentar a los independentistas golpeando la cabeza de historiadores como Josep Fontana, Jaume Sobrequés y otros.

${ }^{128}$ No parece ser el caso del colega francés alienado y alineado voluntaria o involuntariamente con los poderosos comerciantes de esclavos del Antiguo Régimen y denunciado por sus familiares siglos después.

129 Antes del surgimiento del movimiento familiar y social de recuperación de la memoria histórica, ni siquiera se investigaba en concreto - es decir, localmente - la represión, fuera de generalidades sobre el carácter dictatorial del régimen de Franco.

${ }^{130}$ Las investigaciones académicas siguen centradas por lo general en la identificación de las víctimas y los lugares de represión, dejando de lado la información sobre los represores que emana de las fuentes generadas, sobre todo orales, para lo que se aprovecha la argumentación positivista (las fuentes son escritas, o no son), aducida también para nuestra vergüenza por quienes denuncian a los historiadores que buscan la completa verdad (véase la nota 133).

${ }^{131}$ Gracias al valor y la presencia social de los descendientes de las víctimas y otros partidarios de la memoria histórica, que van induciendo posturas más democráticas en partidos, ayuntamientos y otras instituciones.
} 
cial a las democracias latinoamericanas que se pretendió inspirar. La verdad histórica sobre "todos los nombres" implicados en la represión franquista, como víctimas y como verdugos, avanzará ciertamente conforme lo haga la verdad judicial que tiene como finalidad la identificación de los autores de los delitos perseguidos, como se vio en el frustrado Auto de Garzón (2008) y con más claridad todavía en la causa abierta, en base a la justicia universal, contra los crímenes del franquismo por la jueza María Servini en Argentina (2010), que ha ordenado ya la detención de varios torturadores con nombre y apellidos, algunos todavía vivos como Billy el Niño y el capitán Muñecas, puestos en libertad - de momento - por la Sala Penal de la Audiencia Nacional.

La lucha social, política y judicial por una verdad plena sobre el franquismo no será breve: ¿podemos como historiadores esperar años a que otros hagan nuestro trabajo? En honor a nuestro oficio, debería haber un mayor compromiso con la dura batalla que vienen librando las víctimas y sus familias por la verdad, la justicia y la reparación que predica la ONU. El historiador del siglo XX español debería sintonizar más, en su búsqueda de la verdad, con sus objetos de investigación: ejemplos inocentes de un inmenso sufrimiento y lucha por unos valores de libertad, democracia y justicia que son, o deberían ser, los nuestros. No hay caso más claro en que la utilidad de la empatía del historiador con la humanidad de los protagonistas de la historia deviene indispensable si queremos cumplir con nuestros valores historiográficos, profesionales y civiles.

No se trata solamente de poner a discusión hasta dónde ha de llegar nuestro deber en pro de la verdad histórica del franquismo, también tenemos que afrontar situaciones concretas y urgentes: siguen apareciendo casos de investigadores y otros profesionales denunciados judicialmente por dar a conocer nombres de represores, torturadores y las instituciones donde se acogían. ${ }^{132}$ El último caso que hemos tratado en la Academia Solidaria de HaD fue sobre el periodista Gerardo Rivas denunciado, en 2013, por la Falange Española y las JONS por aludir en un artículo de la prensa digital al "amplio historial de crímenes contra la humanidad" de Falange. ${ }^{133}$ La Audiencia Provincial de Madrid archivó la querella con el argumento constitucional

\footnotetext{
${ }^{132}$ Es sabido que la represión franquista durante la guerra y la posguerra siguió un plan sistemático impulsado por el propio Franco, organizado por la Falange y el Ejército Nacional, y apoyado por buena parte de la Iglesia, con la colaboración activa de numerosos jueces de la derecha más conservadora que sigue ejerciendo una influencia nada desdeñable en la magistratura española.

${ }^{133}$ Más información en http://h-debate.com/had-con-gerardo-rivas-3613/.
} 
de la libertad de expresión, pero el temor es libre y estas denuncias, que el ordenamiento jurídico español posibilita, tienen la función manifiesta de mantener vivo un temor colectivo que ahonda sus raíces en la masiva y brutal represión que siguió a la Guerra Civil 1936-1939.

El caso más paradigmático fue el de Dionisio Pereira, 2007-2009, denunciado por la familia del jefe de Falange y primer alcalde franquista de Cerdedo (Pontevedra), Manuel Gutiérrez Torres, citado en las fuentes orales como responsable - o uno de los responsables - de la represión en la localidad, según fue recogido por el denunciado en el libro La II ${ }^{a}$ República e a represión franquista no Concello de Cerdedo (2006). ${ }^{134}$ Finalmente el historiador fue absuelto por la Audiencia Provincial de Pontevedra que hizo valer la libertad de investigación sobre el derecho a la "honra familiar" que aducían los querellantes, que tuvieron la desfachatez de cuestionar la metodología histórica del autor. ${ }^{135}$ La jurisprudencia acumulada por los tribunales de justicia ${ }^{136}$ viene provocando, desde hace años, el archivo de casos y las absoluciones, sin embargo sigue la autocensura en la investigación histórica acerca de los nombres de los autores de los crímenes franquistas, retroalimentada por la expulsión política de Garzón de la Audiencia Nacional, los obstáculos del Gobierno y el Poder Judicial a la querella argentina, y demás supervivencias del franquismo en la justicia, los medios, la Iglesia, la Real Academia de la Historia y el Partido Popular.

El imaginario del miedo puede más que el amor a la objetividad, de modo que continúa siendo en el siglo XXI una actividad épica en España investigar con entera libertad la represión de Estado entre 1936 y 1977. Los historiadores del franquismo, excepto algunos valientes que salvan la imagen y el honor de la profesión, siguen hurtando en sus publicaciones los nombres y apellidos de los causantes de tanta muerte y tortura a lo largo y ancho de España, cuatro décadas después de la muerte de Franco. ¿Dónde queda la autonomía de la historia académica si tenemos que esperar a que políticos y jueces soli-

\footnotetext{
${ }^{134}$ Más información en http://h-debate.com/hi-con-dionisio-pereira-22408/.

135 La metodología histórica más conservadora y positivista, hostil a las fuentes orales, es invocada en favor del presunto criminal; está claro, no hay método científico neutro, quienes lo dicen suelen ubicarse en la parte más negra de la historia y la historiografía, lo sepan o no.

${ }^{136}$ Qué sepamos no tuvo continuación la vergonzosa sentencia de 1980 contra Fernando Ruiz Vergara, director del documental histórico "Rocío" (donde se mencionan los represores de Almonte) que le obligó al exilio en Portugal, donde murió olvidado por la democracia española en 2011. BARROS, Carlos. Historia, memoria y franquismo (2013). En: http://www.h-debate. com/cbarros/spanish/articulos/memoria/Historia_memoria_y_franquismo.htm.
} 
citen a los historiadores datos - que habrá que buscar entonces - de los culpables de los inhumanos delitos cometidos por el franquismo? Se dijo, y con razón, que lo primero son las víctimas pero la justicia, la verdad y la reparación que exigimos en su nombre conlleva la averiguación de los causantes. ¿Puede la historia como disciplina ${ }^{137}$ seguir eludiendo tantos temas espinosos por miedo o comodidad? O lo que es peor, ¿podemos dejar solos a los colegas que fieles al oficio y sus valores se siguen "arriesgando" a investigar y divulgar toda la verdad de la historia?

De cualquier modo la solución tendría que ser más colectiva que individual: ponerse "todos" de acuerdo para procurar y aportar "todos los nombres" en las investigaciones sobre el franquismo. Si eliminamos la parte imaginaria, se verá claramente que el franquismo está históricamente muerto.

Sólo con la verdad combatiremos nuestros fantasmas y haremos avanzar la historia: objetivo de nuestra historiografía de valores.

Recebido: 17/10/2016 - Aprovado: 19/06/2017

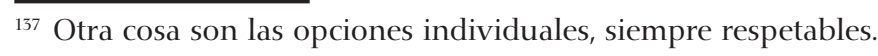

